Nama : Hana Dila Sandy

Nrp : 130219217

$\mathrm{Kp}: \mathrm{B}$

tugas citation

\title{
Medium, Small, and Medium Enterprises and Digital Platforms
}

In July 2020, the Indonesian economic situation face deflation of $0,1 \%$ explained by the Central Bureau of Statistics of the Republic of Indonesia. Furthermore, the tobacco, food, and beverage sector also face the same situation with deflation of $0,79 \%$, following $0.19 \%$ deflation in foodstuff. Deflation happened in demand for food related with the exchange rate of agricultural food crops decreased by $0,74 \%$. Based on the contribution of public expense, $40 \%$ group of lowerclass contributes $17 \%$ of the entire national consumption, and also $40 \%$ group of middle class contributes $36.78 \%$, and $20 \%$ group of upper class contributes $45.49 \%$.

COVID-19 is really affecting people especially people in middle and upper category. They tend to save the money rather than wasting it considering the uncertainty of COVID-19 pandemic ends. Furthermore, people who got termination of employment or were laid off by their company, they leading to decreasing consumption needs and face the depletion of money for daily necessities and sources. Variety of food, transportation, and beverage prices were falling leading to massive demand and deflation. Therefore, there is an inclination for people to return to primary needs instead of tertiary needs so recovery in primary needs will occur faster especially like beverages, food and pharmaceutical products. This uncertainty in spending money is probably going to continue due to the decreasing of income. During COVID-19, people in lower class tend to cut their consumption power and people in upper to middle class tend to hold their consumption power leading to decreasing company income especially small and medium enterprises.

Based on the survey perform by the Central Bureau of Statistics of the Republic of Indonesia in September 2020, there was a decrease within the income of micro and little businesses by $84 \%$ and medium and macro businesses by $82 \%$. This situation affect really hard in variety sector, especially food and beverage, services, accommodation, warehouse, manufacturing, transportation, construction, and trade sectors. Beside that, Asian Development Bank conducted survey in April - May 2020 including 3,831 MSME respondents from 4 countries (Thailand, Philippines, Laos, and Indonesia). The result explained that MSME impact to gross domestic was more than $50 \%$ beside the restrictions that occur in every countries. MSMEs were still running in spite of lower income. Many MSMEs in Indonesia cut down their number of workers from March to June 2020 and still continued until October 2020. Therefore, MSME sectors is extremely urgent during COVID-19 Pandemic. MSME need support to work in digital system economy leading to expand new markets and rise product competitiveness. Utilization of data technology and digitalization is the key for entrepreneurs to survive and support recovery of MSMEs during COVID-19 pandemic. The method digitizing MSMEs unfortunately cannot happen immediately. Join the electronic trade company like Tokopedia, Bukalapak, and Shoppe can be the best way to digitize MSMEs. Ultra-micro financing used digital technology is meant to speed up penetration and financial. This method do to considering that they have complicated factors for access bank. 
This research conducted to answer competitive temperature change within the digital era and changes in new and small business and to see the competitiveness within the digital era in company transformation and technology disruption in new and small business platform.

This research conducted using qualitative research with the aim to figure out the development and progress of MSMEs in Indonesia during COVID-19 pandemic especially decreasing in consumption power and economic recession. The position of researchers, the relationships that are created, procedure that conducted, the role of the context and perception, and the results are all characteristics of this descriptive qualitative research in MSMES that help MSMEs to recover from a market downturn due to the fact that business projects are a social reality created by people's interactions with their surroundings. This qualitative research is focused on the phenomenological method and inductive reasoning, in which a syllogism is constructed based on concrete items or operational evidence from MSMEs in the field and leads to broad conclusions. Qualitative research techniques are used to examine the ongoing social dynamics of MSMEs, as well as the context of the facts that appear on the surface in order to comprehend rather than only clarify the mechanism and facts.

The data is organized into themes and coded to see if the pattern of results is identical. The theoretical structure that has been built can help researchers to connect the data to the research issue. The decline in people's buying power \& companies, and the number of MSMEs that have not yet reached the online domain are all investigated in this qualitative study. This qualitative study uses secondary data to gather enough information to understand the problem and create an analytical structure to address the economic issues that Indonesia faced during the COVID-19 pandemic. The essence of any data that can be revealed, both concrete and hypothetical, is the substance of qualitative data. Behavior-related meanings often contribute to specific outcomes, such as measures that must be implemented to increase public spending and MSMEs. Macro meanings shift from objective to subjective meanings, and micro meanings shift from objective to subjective meanings as well. Objective and subjective meaning, on the other hand, can be both micro and macro. As a result, qualitative research using various data collection methods and relies on triangulation of data provided by three methods: interviews, participant observation, and review notes taken during the interview. The type of interview used in this study is a formal interview with multiple informants who are business actors, Tamanagung villagers, and Sidoarjo residents, using a structure of questions collected by the researcher, and the type of observation used in this study is non-participant observation. The pattern of observations is to make observations at the site of a small and medium-sized business meeting in East Java. This qualitative descriptive study aims to dismantle the current conditions of MSMEs following a pandemic and economic recession, which is linked to the growth of digital technology and financial technology, both of which are becoming increasingly entangled with the microbusiness economy.

Based on current situation, the government should concentrate on controlling the Covid19 reported cases to decline and the public, especially the middle and upper classes to regain trust in going shopping and restoring consumption, given that household consumption expenditures continue to support Indonesia's economic development. Consumption growth can be boosted by a stimulus for social security and assistance to enterprises. The rising consumption and buying 
power of the Indonesian people would keep the country out of recession. The government has also planned a number of scenarios to support small and ultra-micro businesses impacted by Covid-19, including developing MSME safety and rescue plans that include everything from social assistance to tax incentives, credit restructuring, and credit relaxation.

When undergoing transformation by reforming the national economy in order to improve economic growth, avoid the recession caused by the Covid-19 pandemic, one of the government's top priorities must be empowerment and comprehensive support for small businesses. The number of micro and informal businesses is so large that empowering ultra-micro businesses like hawkers and street vendors appears to improve the national economy significantly. In this regard, the government has set aside IDR 28 trillion in the budget to assist 12 million small and ultra-micro enterprises with resources by 2020 . Social security services, such as social assistance, are demandside measures that seek to restore the buying power of the poor and vulnerable to poverty by avoiding a reduction in their purchasing power. The government has initiated a number of economic recovery initiatives, including the distribution of Presidential Assistance for Microbusinesses, the introduction of the MSME website and Digital Market for purchasing domestic MSME goods.

MSMEs in the food sector require access to technology, especially in the production of food and beverages on a small scale in the home kitchen, such as packaging techniques that can extend food storage time, preserve food quality, and keep food healthy throughout the distribution process. The rapid adaptation using internet in Indonesia has sparked hopes for information technology to empower people who have previously been isolated from economic and political centers. More than half of Indonesia's population is now online, and various facets of people's lives are being increasingly linked in the digital space for enterprise, social networking, finance, health care, and education. Digital storage services are available to ultra-micro and micro entrepreneurs in underdeveloped villages who are having trouble obtaining capital from banks. In reality, financial services are critical to the internet economy's development. The use of digital financial services has the potential to propel the internet economy forward while also assisting in the funding of the productive sector. The business players should be able to use the internet to boost productivity, expand the number of products available, and diversify their offerings. Furthermore, the internet will assist ultra-micro and micro businesses in playing a larger role as suppliers in the domestic supply chain, reducing the amount of imported products entering the country.

Due to technological mastery constraints and unequal knowledge of online payment technology, just a few of MSMEs are using digital technology. Planned social engineering should be used to shift MSMEs' working behavior patterns toward working online, beginning with the supply chain system, manufacturing, promotion and marketing, and ending with payment, especially in order to compete with MSMEs from other countries. To make the internet a national and global competitiveness enhancer for Indonesian MSMEs, mature strategies and policies are needed. Technology-based companies seem to continue to synergize with ultra-micro, micro, small, and medium entrepreneurs in order to improve competition in the market. As a result, MSMEs should join the electronic commerce organizers. Since smart phones are becoming more accessible to people from all walks of life, mobile apps can now be used in almost every area of life, including 
shopping, transportation, reservations, and food delivery. Small companies have an advantage over modern retail, which is rife with regulations. Another advantage is that their location, which allows them to reach out to far-flung locations, allows small companies to reach out to a larger number of people than modern retail. Digital technology is becoming more and more interconnected with previously unknown benefits. Bukalapak, Tokopedia, Warung Pintar, and Kiosan, among other start-ups and e-commerce players, are committed to empowering small businesses and MSMEs. Players have used a variety of tactics to encourage small shops and small businesses, including using online bank transfer points for various digital transactions through smart agents, online to offline businesses, and providing education to shop owners or small business owners so that their business operations are handled correctly, efficiently, and effectively.

In Indonesia, digitalization has shown the ability to increase inclusivity and electronification that actually help with economic recovery initiatives like social assistance delivery and MSMEs financing. Electronification allows for more targeted and timely delivery of social assistance, which will boost domestic consumption as the primary driver of national economic development. Payment and finance system digitization has the ability to provide financial access to 62.9 million SMEs and 51 percent of the population (91.3 million people) who do not have access to banking. MSMEs must be constantly aided in their integration into the national production system or the global supply chain. MSMEs must be able to capitalize on local advantages to create exclusive products that will help them compete on both the domestic and foreign markets. Several regions in Indonesia have domestic advantages, such as a plentiful supply of unprocessed marine products, farmland, and plantations, to name a few. To fill the global market, MSMEs must turn these unprocessed goods into special product (Tayibnapis et al., 2021) 


\section{REFERENCES}

Tayibnapis, A. Z., Wuryaningsih, L. E., \& Gora, R. (2021). Medium, Small and Medium Enterprises and Digital Platforms. South Asian Journal of Social Studies and Economics, 10(2), 10-19. https://doi.org/10.9734/sajsse/2021/v10i230258 